\title{
The Early Warning System of the Curve Signal Real-time Monitoring Designed for the Oncoming Cars
}

\author{
Xin-Quan DU \\ Dept. of Traffic Management and Engineering \\ Zhejiang Police College \\ Hangzhou City, China \\ e-mail: duxinquan@zjjcxy.cn
}

\author{
Xin-Ming LIN \\ International School \\ Zhejiang Police College \\ Hangzhou City, China \\ e-mail: linxinming@zjjcxy.cn
}
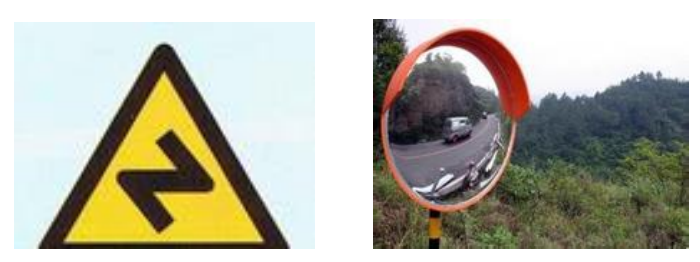

monitored. The equipments are installed in the places about 50 meters ahead of the corner, when the oncoming cars go into the monitoring range, the yellow lights light up or the display screen prompts "Oncoming car" on the opposite direction; when the cars are speeding, the yellow lights in same lane light up or the display screen prompts "Speeding", if no speeding and no car coming from the opposite direction, the green lights brighten or the display screen prompts "Drive cautiously". These signals send timely feedback to the drivers to help them make accurate and timely response, take actions and avoid traffic accidents. This paper selects and designs the information collection and relevant parameters of the early warning system, installation technology, in order to ensure its normal operation.

Keywords-sharp turn; traffic accident; signal lamp; monitoring; early warning

\section{INTRODUCTION}

\section{A. Overview}

The curve usually refers to the road turn, called plane curve in highway engineering. According to the plane curve radius $(\mathrm{R})$ size and design speed of different sizes, it can be divided into general corners and Deflexas.

Deflexa refers to the sudden turn of the road, specifically refers to the design speed less than $60 \mathrm{~km} / \mathrm{h}$, the plane curve radius $(\mathrm{R})$ less than the value, and stopping sight distance (L) less than the following values: The designed speed of $40 \mathrm{~km} / \mathrm{h}$, $1<40, \mathrm{r}<45$; the designed speed $30 \mathrm{~km} / \mathrm{h}, 1<30, \mathrm{r}<20,20 \mathrm{~km} / \mathrm{h}$ speed, $1<20$ curve. The traffic safety law in China, the road safety speed should not exceed $30 \mathrm{~km} / \mathrm{h}$ in Deflexas. In the in Deflexas places traffic accidents are prone, therefore, the common preventive measures are the mirrors with the road traffic signs, as shown below:

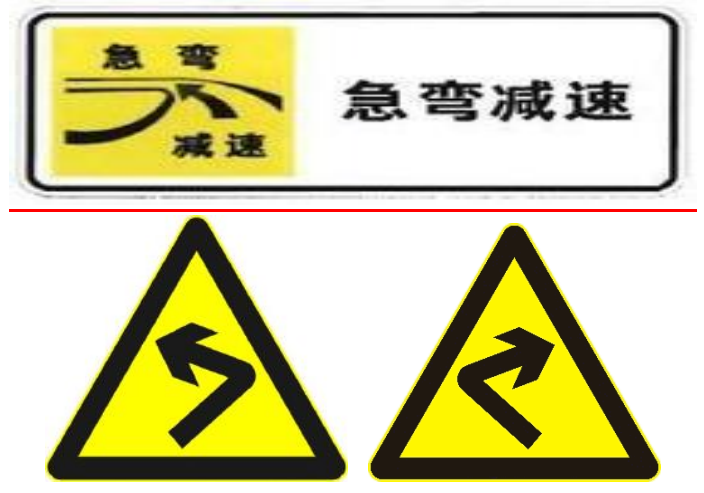

Practice shows that traffic signs can easily be neglected, the mirror image distortion is high, easy to cause the car driver's miscarriage of justice, especially on the mountainous roads where there are often the fog, rain and snow, it is very difficult for the driver to see corner reflector; At night, the driver's sight distance is shorter, and the effect of the curved mirror is almost zero; pollution to the mirror, or no cleaning will lead to the unclear vision; At the same time, the mirror is easy to deform and break, easy to cause visual disorder and other defects, easily lead to accidents. Therefore, it is urgent to develop monitoring facilities to remind the driver the car speed of, and prompt the "oncoming car" to prevent traffic accidents. Taking the initiative to remind drivers' attention as the research object, the real-time monitoring of the car early warning information system designed for the curve has always been put forward to the prevention of traffic accidents, based on the relevant parameters of the system and warning information collection equipment, installation technology for specialized research.

\section{TECHNICAL PRINCIPLES}

The systemic design applies traffic lights, LED display, voice prompts, vehicle speed detection and information transmission and processing technology, these technologies 
are the basic equipments of intelligent transportation, through systemic design, and then repeated experiments; it will eventually become the driver's safety protector when crossing the curve.

\section{A. Traffic Signalling Technology}

there are a variety of very mature products from Traffic signaling technology, the curve early warning information system can choose 300 double lens full screen vehicle light, With: working voltage: AC85V-265V 60hz/50hz; material: die-cast aluminum or PC, according to the GB14887-2011 of People's Republic of China, CE certified products. When radar or vehicle speed detector detects oncoming car arrival information, namely lights on the opposite lane turn into yellow and start 10s delay procedures; when there is no car coming on the opposite lane, the lights will turn into green.

\section{B. LED Display Technology}

LED display is a kind of product to provide information in the form of text or image, in the design of the curve information of the car early warning system has always been in its function is: Full color with high-quality images, and meet all the live TV video signal and text, character display, image processing and computer multimedia show.

The specifications of the outdoor full color display screen pixels: 1R1G; pixel space: $10 \mathrm{~mm}$; brightness: $>5500 \mathrm{~cd} / \mathrm{m}^{2}$; module size: $320 \mathrm{~mm}^{*} 160 \mathrm{~mm}$; visual angle: $120^{\circ}$ horizontal, $120^{\circ}$ vertical; Module resolution: 32*16; working life: $>100,000$ hours; the average power is $230 \mathrm{w} /$ square meters; refresh frequency: 480HZ; pixel density: 10,000/m² drive mode: constant current; visual distance: >10M; materials: Black PC mask, backplane; maximum power: $650 \mathrm{w} / \mathrm{m}^{2}$; input signal: USB; net export.

The specifications of the LED display area can be $800 \mathrm{~mm} * 800 \mathrm{~mm}$ to $1536 \mathrm{~mm} * 1536 \mathrm{~mm}$, to meet the specific requirements of different road conditions; the optional brightness of lights can be 6500-15000 nits, to display the red, green and yellow Chinese characters of the national standard; the LED display screen should be designed, produced and tested with materials in strict accordance with the GBT 23828-2009 standard. The display screen is divided into two regions, the upper region to display the vehicle coming down, the lower region to display the car speeding. Installed in the sharp curves and special complex roads, when there is a car coming up, the top of the screen shows "Oncoming car", When the car is speeding, the lower region of the screen shows that "you have speeding, and starts 10s delay procedures; In the absence of any speeding or "oncoming car", the LED display screen shows "sharp curves, drive carefully", to prompt early warning functions.

\section{The Vehicle Speed Detection Technology}

With the rapid development of computer vision technologies and image processing technologies, real-time image processing based on video detection and radar technology is also a hot research topic in the field of intelligent transportation, and moving vehicle detecting and tracking is the core part of the intelligent transportation system. The design of the car information warning system for the curve has been taking use of the method of real-time vehicle speed detection, to provide the driver with timely data so as to improve the safety of curve driving. At present domestic and international traffic detection or traffic information collection system, a large number of technologies such as the electromagnetic ultrasonic sensing technology, sensor technology, radar technology, and video detection technology have been widely applied. According to the characteristics of the above technologies, the following two programs are proposed through the comparative study:

\section{1)Radar detection technique}

Radar is mainly based on the Doppler effect (Doppler effect) principle, when the target comes close to the radar antenna, the reflected signal frequency will be higher than the frequency of the transmitter; on the contrary, when the target is far away from the antenna to the transmitter, the reflected signal frequency will be lower than the frequency sent by the transmitter. So you can take advantage of the changed numerical of the frequency (when the target is flying towards the radar, Doppler frequency is positive; when the target is flying away from the radar, Doppler frequency is negative.), and calculate the relative speed of the target and the radar, which has already widely used in vehicle speed detection. The relevant parameters are as follows: static measuring range: $5 \sim 300 \mathrm{~km} / \mathrm{h}$; environment requirements: temperature: $-30^{\circ} \mathrm{C}$ to $70^{\circ} \mathrm{C}$; humidity: $0 \% \sim 90 \%$; microwave frequency: $24.15 \mathrm{Ghz}$ (K-band); emission angle: $5^{\circ}$; accuracy: $+/-1 \mathrm{~km} / \mathrm{h}$. lights with other devices.

\section{2) video detection technology}

The video vehicle detector is mainly composed of an outfield camera, a data transmission device and a video processor. One (or more) cameras and lights shoot the road traffic image in a certain direction, then transmit the data through the transmission equipment to the video processor, the speed is calculated by the video processor and displayed on the screen. You can also control the software through interaction, and store the data as the speed detector and detector.

\section{The Voice Prompt Technology}

When the video vehicle detector technologies find out the car is speeding, it prompts through the voice prompting horn installed in the driveway, "you have been speeding".

These technologies mainly play two roles, one is when the car goes into the corners of the curve, radar tester or video vehicle detector automatic measures and displays speed on the LED display, "you have been speeding" or start the voice prompt system in the lane to remind the driver to slow down; Two is to send the oncoming car information to the driver on the opposite lane with the yellow light on the opposite lane, or with LED display showing "Oncoming car", and start the 10s delay program, to warn each other. The signal processes are shown in Figure 1, 2: 


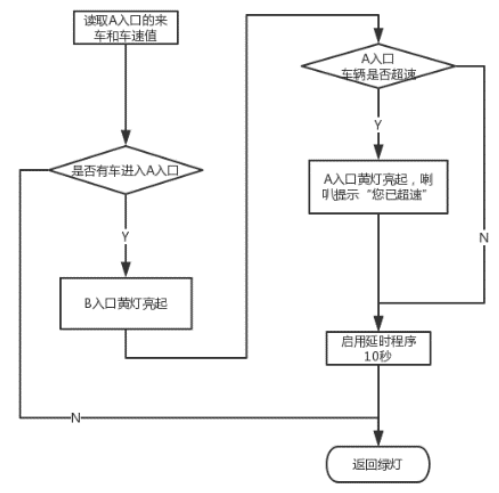

Figure 1 flow chart of traffic light signals

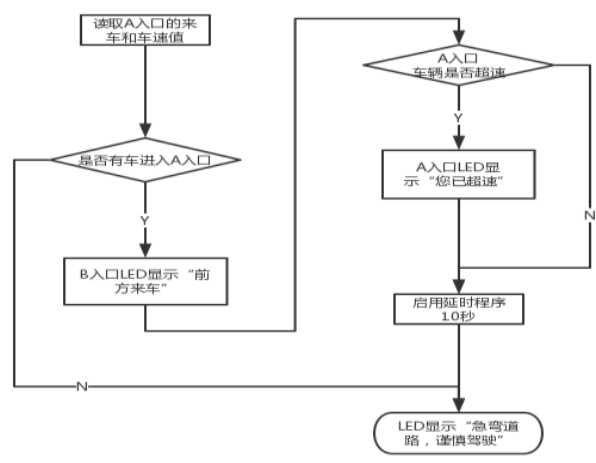

Figure 2 flow chart of LED display signal

\section{DESIGN AND INSTALLATION}

\section{A. Installation of Signal Lights in Curves;}

According to the national standard GB14886 of People's Republic of China, 2006 Road Traffic Signal Setting and Installation Specifications, the location of the installation of the curve signal lamp should be right directed at the controlled lane, its location and height shall comply with the following requirements:

1) installation position of the signal lamp

The signal lamps are, generally, installed in the side of the curve lane with the use of a cantilever, prompting drivers and pedestrians that they should look and then pass only after confirming the curve is secure for them. The curve traffic warning lights should be set up according to the curve shape, so the orientations of the signal lamp is on both sides of the corners in the vision, the signal lamp should be set toward the vicinity of the center point of the curve, the purpose is to make the warning lights visible to the drivers on both ends of the curve.

2) the installation height of curve signal lamp

The installation height of the cantilever: $5.5 \mathrm{~m}-7 \mathrm{~m}$; the height of the column installed should not be lower than $3 \mathrm{~m}$; if installed on the overpass, the installation height shall not be less than the bridge clearance as shown in Figure 3:

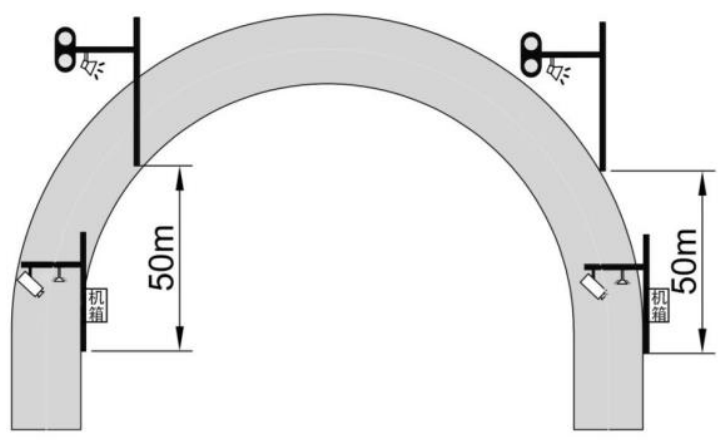

Figure 3 curve signal lamp installation

\section{B. Installation Curve LED Display}

Generally, LED display screen in the curve is not large, the installation structure should give full consideration to the factors such as wind, earthquake, load bearing capacities etc.; The second is the screen body, shape, structure, decoration and coordination with the attached bar or object; furthermore, to consider the local environmental factors, ratio of air humidity, salt content of air and so on, as shown in Figure 4:

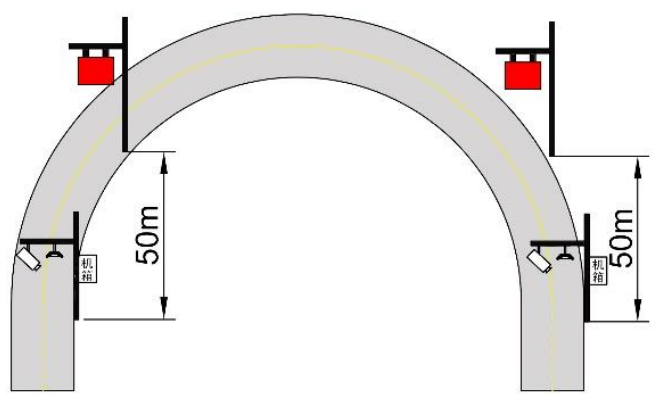

Figure 4 installation of LED display screen in the curve

\section{Installation of Vehicle Speed Monitor in the Curve \\ 1) the installation of radar detector}

Generally, a radar detector and a fill-in light is installed on the beam of a t-shaped bar inside the curve. The velometer and pavement angle should not exceed 30 degrees. Consideration should be given to the detecting distance of the radar velometer and the height of vehicle on the road, the T-shaped bar should not too low, or it will affect the traffic; if it is too high, the radar cannot detect. The height of the cross bar is generally set as $4-8 \mathrm{~m}$. Data transmission equipments and power supply equipments are installed in the box on the upright column.

2) the installation of video detector

The video detector is installed on the off side and requires only cameras and data transmission equipments. Generally, a camera and lights are installed on the beam of the T-shaped 
bar to capture image from one direction. The data transmission equipments and power supply equipments are installed in the chassis in the upright column. The video processor is arranged in the chassis, the detected traffic information is transmitted to the processor, and then the processed information will be transmitted to the signal lamps or on the LED display in the curve. The advantages of video detector are as follows: the system is flexible in actual use, simple in installation, convenient in use, no damage to the pavement, lane close not required in times of maintenance, as shown in Figure 5:

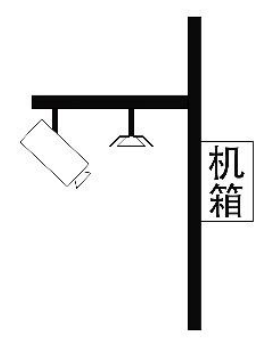

Figure 5 installation diagram of vehicle speed monitor in the curve

\section{The Installation of Voice Prompt System}

The horns of the voice prompt system is installed on the cantilever of the curve signal lamp, and connected with the video vehicle detector as shown in Figure 6:

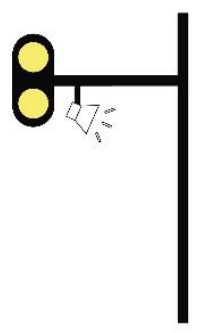

Figure 6 the voice prompt system installation

\section{CONCLUSION}

The curved roads are prone to serious traffic accidents because of its special geographical location, the driver's sight is greatly affected, coupled with the existing road design deficiencies, which has been a difficult and important problem for the traffic management departments. However, for a long time, the research on this is few, and most of them are to prevent traffic accidents from the installation guardrail and curved reflector, and the proposal of a comprehensive, workable scheme is less. Through the study of technologies and products, the comprehensive application of the reminding signal lamp, LED display, voice prompt system take vehicle speed monitoring technology improves the traffic safety of the curved road fundamentally, instead of the previous single, passive protection, the traditional way to reduce traffic accidents.

\section{REFERENCES}

[1] People's Republic of China road traffic safety law. The Eleventh National People's Congress of the twentieth meeting of the Standing Committee amendment.May.1, 2011.

[2] GB14887-2011. People's Republic of China national standard--traffic lights.

[3] GB 14886 - 2006. People's Republic of China national standard--road traffic signal setting and installation specification

[4] Ma Huiming. Review of the detection speed. North Central University (Natural Science Edition), vol. 28,2007.

[5] GBT21255-2007. People's Republic of China national standard--motor vehicle speed measuring instrument.

[6] Patent to be granted. 